\title{
Фотопорог слоистого кристалла $\alpha$-GeS: расчет из первых принципов
}

\author{
(C) З.А. Джахангирли ${ }^{1,2}$, Ф.М. Гашимзаде ${ }^{1}$, Д.А. Гусейнова ${ }^{1}$, Б.Г. Мехтиев ${ }^{1}$, Н.Б. Мустафраев $^{1}$ \\ ${ }^{1}$ Институт фризики Национальной академии наук Азербайджана, \\ AZ-1143 Баку, Азербайджан \\ ${ }^{2}$ Азербайджанский технический университет, \\ AZ-1143 Баку, Азербайджан \\ E-mail: zakircahangirli@yahoo.com
}

(Получена 4 апреля 2017 г. Принята к печати 29 ноября 2017 г.)

Из первых принципов на основе метода функционала плотности рассчитан фотопорог слоистого кристалла $\alpha-\mathrm{GeS}$ в зависимости от его толщины. Для моделирования кристалла конечной толщины использовался метод периодических пластин. Две соседние кристаллические пластины, состоящие из нескольких слоев, разделялись вакуумом толщиной в 4 слоя, что соответствует удвоенному размеру элементарной ячейки объемного кристалла. Показано, что при толщине кристалла более 10 слоев величина фотопорога практически не меняется.

DOI: $10.21883 /$ FTP.2018.07.46037.8602

\section{1. Введение}

Слоистый кристалл сульфида германия - один из перспективных полупроводниковых соединений группы $\mathrm{A}^{\mathrm{IV}} \mathrm{B}^{\mathrm{VI}}$ с точки зрения применения в оптоэлектронике, телекоммуникации, вычислительной технике и солнечной энергетике. Важным его свойством является гораздо более низкая токсичность и меньшее воздействие на окружающую среду по сравнению с полупроводниками, изготовленными из кадмия, свинца и ртути. Он является менее дорогостоящим, чем материалы, сделанные из редких и благородных металлов. Стеклообразный $\mathrm{GeS}$ используется в лазерах, волоконно-оптических устройствах и инфракрасных линзах, а также оптических перезаписываемых дисках и энергонезависимых запоминающих устройствах. $\mathrm{GeS}$ также широко используется в качестве твердого электролита в оперативных запоминающих устройствах. Изготовление наноструктур на основе GeS может еще более расширить возможности практического применения данного материала. Изготовленные из $\mathrm{GeS}$ нанослои и нанопроволоки демонстрируют выдающуюся фоточувствительность [1], что указывает на возможное использование их в системах преобразования солнечной энергии, например при изготовлении фотовольтаических устройств.

Кристаллическая структура $\mathrm{GeS}$ (рис. 1 [2]) при атмосферном давлении состоит из четырех атомных плоскостей, расположенных в последовательности $\mathrm{Ge}-\mathrm{S}-\mathrm{S}-\mathrm{Ge}$. Элементарная ячейка кристалла содержит два слоя, переходящих друг в друга под действием операции инверсии. Согласно [3], координаты атомов внутри элементарной ячейки, выраженные в долях параметров решетки $a=4.299 \AA, b=3.646 \AA, c=10.481 \AA$, следующие: $\pm(x, 1 / 4, z ; 1 / 2-x, 1 / 4,1 / 2+z), x_{\mathrm{Ge}}=0.1277$, $z_{\mathrm{Ge}}=0.1221, x_{\mathrm{S}}=0.5023, z_{\mathrm{S}}=0.8495$. Пространственная группа симметрии $P$ cmn- $D_{2 h}^{16}$, номер пространственной группы 62.
Знание величины фотопорога необходимо для определения контактной разности потенциалов в гетероструктурах, применяемых в качестве преобразователей солнечной энергии. Нам известна всего одна работа, в которой из первых принципов рассчитан фотопорог только для монослойной толщины $\mathrm{GeS}$ [4]. Настоящая

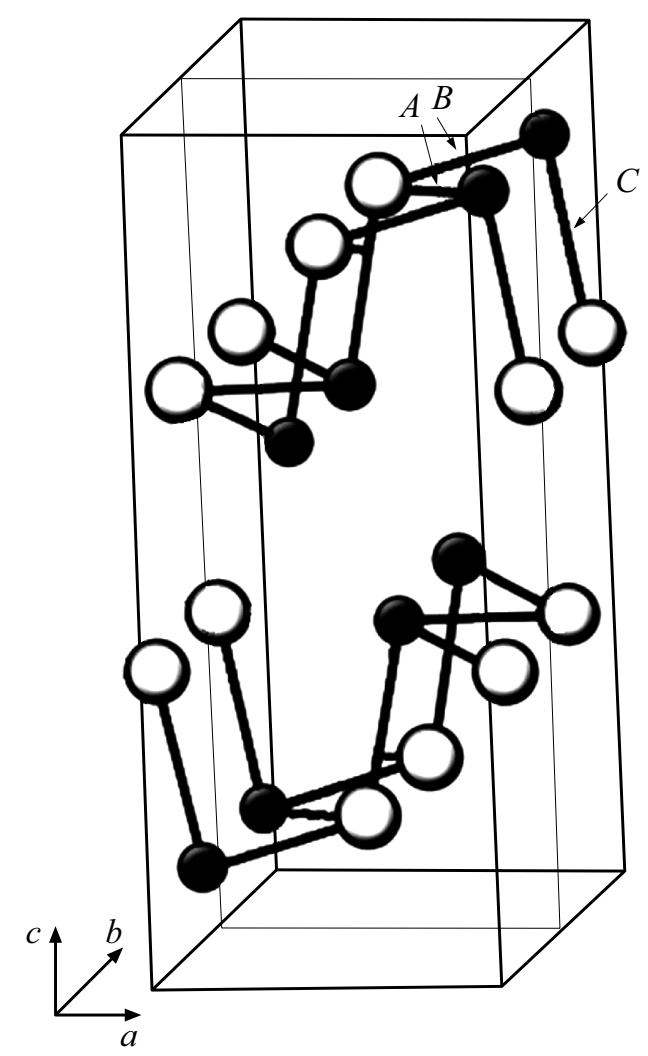

Рис. 1. Кристаллическая структура GeS [2]. Показаны две элементарные ячейки. Атомы $\mathrm{Ge}$ и $\mathrm{S}$ изображены в виде маленьких и больших сфер соответственно. Плоскость слоев перпендикулярна оси $c$. 
работа посвящена расчету фотопорога для различных толщин полупроводникового кристалла $\mathrm{GeS}$.

\section{2. Метод расчета}

Кристаллы конечных толщин моделировались сверхрешеткой из суперьячеек кристаллов $\mathrm{GeS}$, состоящих из нескольких слоев кристалла с вакуумом между ними. Наши оценки показали, что толщина вакуума $\sim 20 \AA$ достаточна для пренебрежения взаимодействием соседних суперьячеек. Реально мы строили сверхрешетку из одной, двух и более элементарных ячеек кристалла GeS, а вакуум брали толщиной в две элементарные ячейки. В результате получали вакуумный промежуток шириной $\sim 22.9 \AA$.

Расчет проведен в рамках теории функционала плотности в базисе плоских волн, реализованного в пакете программ ABINIT [5]. Обменно-корреляционное взаимодействие описывалось в приближении локальной плотности (LDA) по схеме [6]. Численное интегрирование по зоне Бриллюэна проводилось с помощью разбиения $10 \times 10 \times 1$ со сдвигом $(0.5,0.5,0.5)$ от начала координат, согласно схеме Монкхорста-Пака [7]. В качестве псевдопотенциалов использовались сохраняющие норму псевдопотенциалы Хартвигсена-Гоэдеккера-Хаттера [8]. В разложении волновой функции были учтены плоские волны с максимальной кинетической энергией до 1350 эВ, которые обеспечивают хорошую сходимость полной энергии. Равновесные значения параметров определены путем минимизации полной энергии с точностью $10^{-5}{ }_{\ni} \mathrm{B}$ на элементарную ячейку. При этом равновесные положения атомов внутри элементарной ячейки кристалла определялись минимизацией сил Гелманна-Фейнмана, действующих на атомы. Процедура минимизации проводилась до тех пор, пока не достигалось значение модуля сил, меньшее 1 мэВ/А. Такая процедура особенно необходима для рассматриваемых сверхструктур, поскольку межатомные расстояния подвержены релаксации вблизи границы с вакуумом.

\section{3. Обсуждение результатов}

На рис. 2 приведен вид потенциала для случая 10 слоев или 40 атомных плоскостей в направлении, перпендикулярном слоям. Толщина кристалла равна $48.2 \AA$, а вакуума $-22.9 \AA$. Теоретически рассчитанное значение положения максимума валентной зоны по отношению к вакууму для монослоя составляет $\sim-5$ эВ [4] (из гистограммы, приведенной в [4] на рис. 5, оценить более точно невозможно), что близко к найденному нами значению 4.99 эВ для кристалла толщиной в 2 слоя. Мы рассчитали зависимость величины фотопорога от толщины кристалла GeS. Результаты расчета приведены на рис. 3. При толщине кристалла более 10 слоев величина фотопорога практически не меняется.

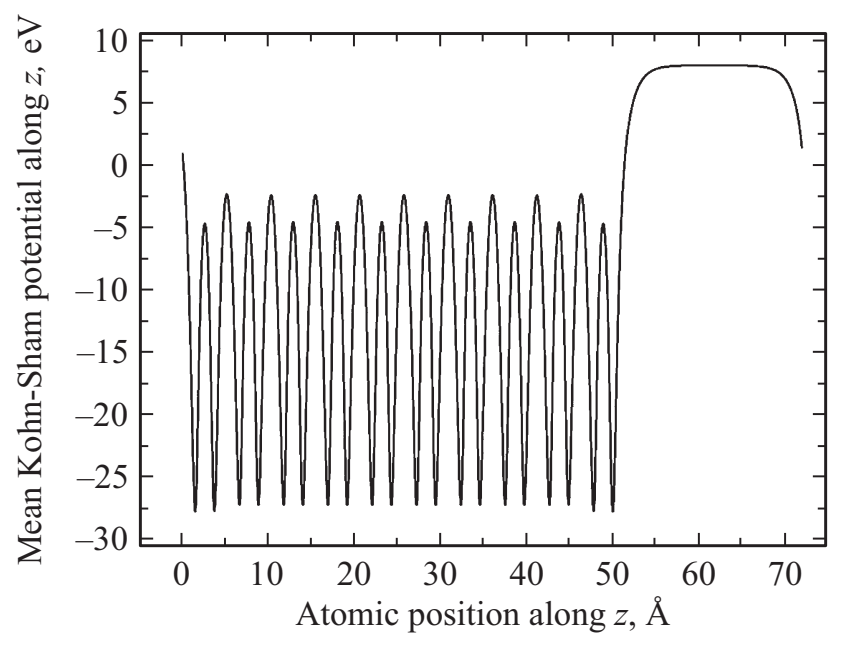

Рис. 2. Вид потенциала для случая 10 слоев или 40 атомных плоскостей в направлении, перпендикулярном слоям. Толщина кристалла равна $48.2 \AA$, а вакуума - $22.9 \AA$.

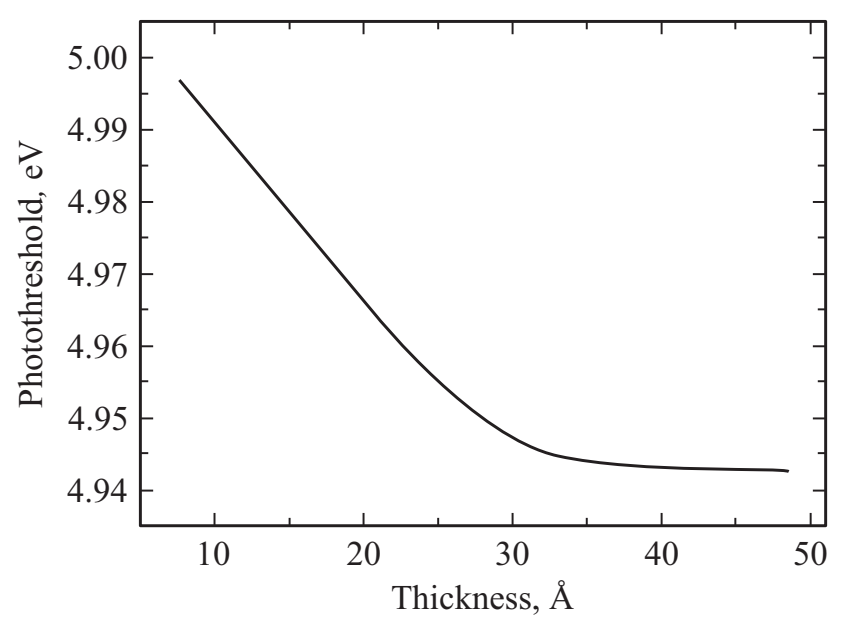

Рис. 3. Зависимость величины фотопорога от толщины кристалла $\mathrm{GeS}$.

В работе [9] рассчитано относительное положение валентных зон в гетероструктуре $\mathrm{GeS} / \mathrm{SnS}$ методом сверхрешетки, составленной из большого числа слоев $\mathrm{GeS}$ и $\mathrm{SnS}$. Мы рассчитали методом, изложенным здесь, фотопорог также для $\mathrm{SnS}$ и оценили смещение валентных зон для контакта $\mathrm{GeS} / \mathrm{SnS}$ как разность их фотопорогов и получили значение 0.33 эВ, что неплохо согласуется с результатом вышеуказанной работы $(0.41$ эВ).

\section{4. Заключение}

Рассчитана толщинная зависимость фотопорога кристалла $\alpha$-GeS. Результаты расчетов могут быть применены для анализа экспериментов по дифракции электронов, рентгеновской фотоэлектронной спектроскопии и электролюминесценции кристаллов $\mathrm{GeS}$ нанометрических толщин. 
Авторы выражают благодарность А. Бондякову (Объединенный институт ядерных исследований, Дубна, Россия), а также всему коллективу проекта AZGRID за техническую поддержку теоретических расчетов, проведенных для данного исследования.

Все результаты расчетов, представленные в данной статье, получены в дата-центре (AZGRID) Института физики НАН Азербайджана.

\section{Список литературы}

[1] L. Shi, Y. Dai. J. Appl. Cryst., 47, 527 (2014).

[2] H.C. Hsueh, M.C. Warren, H. Vass, G.J. Ackland, S.J. Clark, J. Crain. Phys. Rev. B, 53, 14806 (1996).

[3] H. Wiedemeier, H. G. von Schnering. Z. Kristallogr., 148, 295 (1978).

[4] A.K. Singh, R.G. Hennig. Appl. Phys. Lett., 105, 042103 (2014).

[5] X. Gonze, B. Amadon, P.-M. Anglade, J.-M. Beuken, F. Bottin, P. Boulanger, F. Bruneval, D. Galiste, R. Caracas, M. Côte, T. Deutsch, L. Genovese, Ph. Ghosez, M. Giantomassi, S. Goedecker, D.R. Hamann, P. Hermet, F. Jollet, G. Jomard, S. Leroux, M. Mancini. Comput. Phys. Commun., 180, 2582 (2009).

[6] S. Goedecker, M. Teter, J. Hutter. Phys. Rev. B, 54, 1703 (1996).

[7] H.J. Monkhorst, J.D. Pack. Phys. Rev. B, 13, 5188 (1976).

[8] C. Hartwigsen, S. Goedecker, J. Hutter. Phys. Rev. B, 58, 3641 (1998).

[9] B.D. Malone, E. Kaxiras. Phys. Rev. B, 87, 245312 (2013).

Редактор Г.А. Оганесян

\section{Photothreshold of layered crystal $\alpha$-GeS: first-principles calculation}

Z.A. Jahangirli ${ }^{\mathbf{1} 2}$, F.M. Hashimzade ${ }^{1}$, D.A. Huseynova ${ }^{1}$, B.G. Mehdiyev' ${ }^{1}$, N.B. Mustafaev'

${ }^{1}$ Institute of Physics of the National Academy of Sciences of Azerbaijan, AZ-1143 Baku, Azerbaijan

2 Azerbaijan Technical University, AZ-1143 Baku, Azerbaijan

Abstract The photothreshold of a layered crystal $\alpha-\mathrm{GeS}$ as a function of its thickness were studied from first principles using the density functional theory based of the periodic slab supercell model. Two adjacent crystal slabs consisting of several layers were separated by a vacuum region of four-layer width, which corresponds to a doubles size of the unit cell of a bulk crystal. It is shown that for layers thicker than 10 layers the photothreshold does not depend on the layer thickness. 